\title{
COLEÇÃO AUTORAL DE JOIAS: UMA \\ EXPERIÊNCIA PRÁTICA A PARTIR DA \\ RECICLAGEM ARTESANAL DE POLÍMEROS
}

\section{AUTHORIALJEWELRYCOLLECTION:APRACTICALEXPERIENCEBYHANDMADEPOLYMERRECYCLING}

\author{
CHIARA ALINE BEPPLER | UNIVILLE \\ ISADORA BURMEISTER DICKIE, Dra. | UNIVILLE \\ ADRIANE SHIBATA SANTOS, Dra.| UNIVILLE
}

\begin{abstract}
RESUMO
O plástico se tornou um dos materiais cujos resíduos mais agridem o meio ambiente, isso devido tanto às suas propriedades e características, como também pela quantidade gerada a cada ano. Observa-se um aumento exponencial no consumo de produtos plásticos, porém sua reciclagem e reutilização se mantêm estagnadas. Assim, para que deixe de ser um problema, é essencial que a gestão do seu uso e descarte seja reformulada. Este artigo apresenta os resultados de um trabalho de conclusão de curso em Design que visou o desenvolvimento de uma coleção autoral de joias, a partir da reciclagem artesanal de resíduos plásticos. A metodologia projetual aplicou as etapas propostas por Hanington e Martin (2012), enfatizando a experimentação do material plástico, essencial para a composição final da coleção. Como resultado, a coleção elaborada a partir de embalagens de plástico PEAD procura disseminar a cultura de um ciclo sustentável de consumo, assim como a ressignificação deste material.
\end{abstract}

PALAVRAS CHAVE: Resíduos plásticos; Design sustentável; Design de acessórios

\begin{abstract}
Plastic has become one of the materials whose residues are most damaging to the environment, due both to its properties and characteristics, as well as the amount generated each year. There is an exponential increase in the consumption of plastic products, however, its recycling and reuse remain stagnant. Therefore, to stop being a problem, it is essential to reformulate the use and disposal management. This article presents the results of the course conclusion work in Design whose objective was to develop an authorial jewelry collection from the artisanal recycling of plastic waste. The design methodology applied the steps proposed by Hanington and Martin (2012) were applied, emphasizing the experimentation with plastic, essential for the final composition of the collection. As a result, the collection produced from HDPE plastic packaging, which aims to disseminate the culture of a sustainable consumption cycle, as well as the resignification of this material.
\end{abstract}

KEY WORDS: Plastic waste; Sustainable design; Design of accessories 


\section{INTRODUÇÃO}

O plástico, material desenvolvido no início da década de 1920, veio para revolucionar diversos âmbitos da sociedade: da medicina às principais tecnologias utilizadas no cotidiano. Dificilmente é possível imaginar como essa e outras áreas teriam progredido sem o uso dos polímeros sintéticos. Passados mais de meio século de seu descobrimento, e com o aumento exponencial da população mundial, observa-se a propagação dos polímeros por meio de um crescimento elevado de sua aplicação e consumo.

As discussões acerca de um modelo de produção e consumo em equilíbrio com os recursos disponíveis iniciaram em contrapartida à industrialização já no século XIX, porém apenas em 1972 a Organização das Nações Unidas realizou a primeira conferência mundial sobre o meio ambiente. A partir dela, outras conferências foram realizadas e vieram a definir o conceito de desenvolvimento sustentável como o desenvolvimento pensado para a utilização consciente de todos os recursos naturais, atendendo às necessidades das gerações atuais e das futuras (ONU, 2019, web).

O Design está diretamente ligado ao desenvolvimento de produtos e por isso tem grande responsabilidade na construção de uma cultura de consumo e de desenvolvimento sustentável. Uma das vertentes do Design que se encarrega de ilustrar pontualmente a sustentabilidade é o Design Sustentável. Segundo Pazmino (2007), trata-se de um processo que deve considerar a viabilidade econômica, equidade social e as práticas ecologicamente corretas no desenvolvimento de um produto.

Tendo em vista o impacto ambiental gerado pelos resíduos plásticos, a necessidade da produção e consumo sustentáveis, foi desenvolvido em 2019 um Trabalho de Conclusão de Curso de Design com a problemática referente a como o design de produtos pode tornar o uso dos resíduos plásticos parte de um ciclo sustentável de consumo.

Pesquisas mostram o perigo da poluição plástica para a manutenção da vida no planeta, consequentemente uma ameaça para a vida humana. Problema que poderia ser diminuído ou até totalmente resolvido com uma política de reciclagem abrangente, que envolveria desde o princípio da fabricação de produtos que levam plástico, ao ciclo completo de distribuição, varejo, uso e retorno aos fabricantes ou outras organizações para reciclagem e transformação em novos produtos/ materiais.

Os resultados do Trabalho de Conclusão de Curso, apresentados neste artigo, convergem para o desenvolvimento de uma coleção de acessórios de moda a partir da reciclagem artesanal de resíduos plásticos, visando o papel do Design de Produtos na propagação da cultura de reciclagem e do ciclo sustentável de consumo.

A metodologia utilizada no desenvolvimento do projeto baseou-se nas etapas propostas por Hanington e Martin (2012), sendo elas: (i) Planejamento, Escopo e Definição: etapa que correspondeu à elaboração do projeto, bem como à condução de uma pesquisa bibliográfica para aprofundamento teórico sobre polímeros e reciclagem artesanal; (ii) Exploração, Síntese e Implicações de Design: etapa que correspondeu à investigação e análise de métodos de reciclagem artesanal de polímeros, a uma análise sincrônica de produtos similares (ou seja, acessórios plásticos) e à definição de usuário; (iii) Geração de Conceito: etapa na qual foi elaborada a proposta conceitual da coleção a partir de experimentações visuais com os materiais, painel de conceito e geração de alternativas, incluindo a confecção de protótipos iniciais; por fim, (IV) Prototipagem: etapa que correspondeu a experimentações com o polímero reciclado, sendo listados os materiais utilizados, e então realizados os protótipos finais das peças da coleção autoral de joias.

As autoras ressaltam que este conteúdo se trata de uma ampliação do artigo "Reciclagem artesanal de polímeros para aplicação no desenvolvimento de coleção de acessórios de moda", aprovado e apresentado no VIII ENSUS - Encontro de Sustentabilidade em Projeto.

No tópico 2 deste artigo é apresentada a síntese da fundamentação teórica, resultante de pesquisa bibliográfica como parte dos procedimentos adotados na etapa de Planejamento, Escopo e Definição do Projeto. O tópico 3 aborda os procedimentos metodológicos adotados no desenvolvimento projetual, enquanto o tópico 4 apresenta os principais resultados obtidos no processo de reciclagem artesanal do PEAD. Por fim, é apresentada a discussão que visa disseminar a cultura de um ciclo sustentável de consumo, assim como a ressignificação deste material.

\section{DESIGN E O CONSUMO SUSTENTÁVEL DO PLÁSTICO: DA PRODUÇÃO E USO À RECI- CLAGEM E RESSIGNIFICAÇÃO}

O descobrimento dos polímeros na forma sintética possibilitou o desenvolvimento de diversas tecnologias, assim como avanços na área da medicina, na indústria têxtil e outros diversos setores. Segundo Nunes e Lopes (2014, p. 41), "O surgimento de polímeros sintéticos [...] contribuiu muito para a revolução tecnológica pela qual passamos atualmente". Por meio das diferentes pesquisas, no decorrer das décadas, novas variações de polímeros foram desenvolvidas, introduzindo ao mercado plásticos hoje comumente usados 
como o Poliuretano (PU), Polietileno de Alta Densidade (PEAD), Polipropileno (PP) e o Policarbonato (PC), todos introduzidos nos anos 1950 (NUNES e LOPES, 2014).

Os polímeros sintéticos apresentam características que conseguem atender diferentes demandas, trazendo enormes benefícios econômicos aos diversos setores em que se encontram, por juntar versatilidade, baixo-custo, durabilidade e uma alta relação entre força-peso. Essa combinação de fatores gerou um crescimento exponencial em seu uso, atingindo 311 toneladas produzidas em 2014; a previsão é que esse número dobre até 2050. Entre os plásticos que mais circulam, estão incluídos os destinados para a fabricação de embalagens, que representam cerca de $26 \%$ da produção mundial de polímeros. Os tipos de plásticos mais usados para embalagens são o PET (Politereftalato de Etileno), PEAD (Polietileno de Alta Densidade), PP (Polipropileno) e EPS (Poliestireno expandido) (ELLEN MACARTHUR FOUNDATION, 2016).

A repercussão positiva que o descobrimento dos polímeros sintéticos obteve ao longo do tempo vem sendo contraposta ao enorme impacto ambiental que o material promove. Uma de suas mais valorizadas propriedades, a durabilidade do material, tornou-se um dos maiores impasses que atingem o meio ambiente e seus ecossistemas. O aumento do consumo de plástico nos dias atuais é favorecido pelo crescimento exponencial da população e pela praticidade proporcionada por embalagens plásticas; consequentemente, a quantidade de resíduos descartados anualmente é alarmante.

No mundo são produzidas anualmente cerca de 300 milhões de toneladas de plástico e apenas 14\% dessa quantidade é coletada para a reciclagem e reutilização (ONU, 2019). Cerca de 13 milhões de toneladas de plástico vão parar nos oceanos todos os anos. Isso afeta diretamente a manutenção da vida no planeta, prejudicando milhares de ecossistemas. Pesquisas apontam que os oceanos carregam atualmente mais de 150 milhões de toneladas de plástico, sendo que até 2025 haverá uma tonelada de plástico para cada três toneladas de peixe. Se nada mudar até 2050 devemos esperar mais plástico do que peixes nos oceanos (ELLEN MACARTHUR FOUNDATION, 2016). Das nove bilhões de toneladas do material já produzidas na história, apenas 9\% foi reciclada, sendo que metade dessa quantidade tem como origem plásticos utilizados para fabricação de embalagens. Calcula-se que se o consumo de polímeros continuar na mesma intensidade, em 2050 cerca de 12 bilhões de toneladas de lixo plástico estarão presentes no meio ambiente, em lixões e aterros sanitários (UN ENVIRONMENT, 2018).

O uso linear do plástico, ou seja, o pensamento de que em certo momento esse material de inúmeras qualidades se torna apenas lixo, traz enormes impactos para o planeta e consequentemente para a sociedade, como apontado anteriormente. $O$ descarte, mesmo que conduzido por órgãos capacitados, tem destinos impróprios e os resíduos coletados acabam sendo conduzidos aos oceanos. O Brasil não possui, na totalidade de seu território, sistemas de coleta seletiva (caracterizada por fazer a distinção de resíduos), apenas 70,9\% de seus municípios possuem algum tipo de iniciativa, sendo que os que possuem não garantem o serviço em toda sua área urbana (ABRELPE, 2018). Em locais que a coleta seletiva não atua, a reciclagem de plásticos e outros resíduos recicláveis fica totalmente a cargo de catadores de materiais, hoje responsáveis por recolher 90\% de todo lixo reciclado no Brasil (IPEA, 2013).

Ainda no Brasil, apenas $22 \%$ desse material é reciclado e reinserido na produção de novos produtos. $O$ processo de reciclagem mais utilizado é o processo mecânico, que pode se dividir em reciclagem primária (pós-industrial) e secundária (pós-consumo). A reciclagem pós-industrial se caracteriza pelo processamento do material que se encontra ainda dentro da indústria, resíduos provenientes de rebarbas, peças defeituosas, etc. Por se tratar de um material normalmente sem contaminação de outros resíduos, sua reinserção na indústria é facilitada, sendo esse um material de alto valor no mercado. Já a reciclagem secundária, de pós-consumo, é referente ao plástico já utilizado pelo usuário, resultante, em sua maioria, do descarte de embalagens.

Neste contexto, a sociedade ainda enfrenta muitos problemas para implementar processos que estejam alinhados aos princípios da sustentabilidade. Isso se dá, em grande parte, pelos perpetuados padrões de alto consumo e pelo modelo atual de produção de bens que depende, em sua maioria, da utilização de combustíveis fósseis. Esse padrão tende a se agravar quando a população de determinado país enriquece, gerando assim mais consumo que, consequentemente, aumenta a emissão de gases, resíduos e o descarte destes (DIAS, 2015).

$O$ design pode ser um agente transformador neste cenário, uma vez que tem papel fundamental na criação de novos produtos e consequentemente, na propagação de uma cultura sustentável de consumo. Por meio do Design Sustentável, o processo de desenvolvimento de um produto deve considerar sua viabilidade financeira, a equidade social e o equilíbrio ecológico (Pazmino, 2007).

Manzini e Vezzoli (2008 p. 9) também já destacavam que "[...] o papel do design industrial pode ser resumido como uma atividade que conecta o tecnologicamente possível com o ecologicamente necessário e tende a dar origem a novas proposições socioculturais significativas", ou seja, o Design carrega a importante oportunidade de 
unir necessidades ecológicas com tecnologias viáveis para instauração de importantes mudanças sociais.

$\mathrm{O}$ atual modelo de produção e consumo tem contribuído com a degradação socioambiental do planeta. Assim, para a construção de um mundo sustentável, a redução do consumo é essencial, bem como incentivar formas de se repensar como se consome. Um ciclo sustentável de consumo requer um modo de produção que visa diminuir os desequilíbrios socioambientais em toda a trajetória de um produto, desde sua fabricação ao reaproveitamento de seus materiais após o descarte pelo usuário (ZANIRATO e ROTONDARO, 2016).

Ao contrário do modelo linear de extração, transformação, consumo e descarte, o modelo circular é regenerativo e restaurativo, visando produtos, componentes e materiais em seu mais alto nível de utilidade e valor (ELLEN MACARTHUR FOUNDATION, 2015). Este modelo deve ser trabalhado para a inclusão da diversidade de culturas e soluções, atentando-se sempre ao contexto local e às necessidades dos usuários, para assim estabelecer a direção para o desenvolvimento de produtos (GEGER e TENNENBAUM, 2017).

O modo como as pessoas se relacionam com os objetos pode contribuir com a valorização de produtos e materiais em contraponto à cultura do descarte promovido pelo modelo linear de produção. Considerando a relação e significado dados a artefatos durante a história da humanidade, observa-se uma ligação com o repertório existente em relação às coisas que estão à nossa volta. 0 design tem um grande desafio em sua operação, que é o de agir como propulsor de transformação. Diante do grande problema da obtenção de matérias-primas virgens, do descarte inapropriado do plástico e dos impactos ambientais causados por estes, o design tem o papel de agir como agente de ressignificação desses materiais (BELCHIOR, 2017).

Joias e acessórios foram, por muitos séculos, comumente fabricados a partir de materiais nobres como ouro, prata e pedras preciosas, sendo consideradas símbolos de riqueza e status. Com o descobrimento de materiais diversos, surgiram alternativas mais econômicas para as matérias-primas preciosas. As matérias-primas virgens tendem a se tornar cada vez mais escassas, tornando seu processo de obtenção extremamente caro e de grande impacto ambiental.

O Design como disciplina é um importante protagonista no desenvolvimento de produtos, tendo um papel de grande relevância na ressignificação de materiais. Dispondo de uma posição de decisão, ou pelo menos de enorme peso na escolha da utilização e aplicação de materiais, o designer se torna uma figura essencial no emprego da ressignificação.

\section{PROCEDIMENTOS METODOLÓGICOS}

O projeto de desenvolvimento da coleção autoral aplicou as etapas metodológicas propostas por Hanington e Martin (2012). Desta forma, foi dividido em quatro etapas: (i) Planejamento, Escopo e Definição; (ii) Exploração, Síntese e Implicações de Design; (iii) Geração de Conceito; e (iv) Prototipagem.

Inicialmente, e em cumprimento à primeira etapa proposta por Hanington e Martin (2012), foi realizada uma pesquisa bibliográfica, que resultou na fundamentação teórica apresentada de forma sintética no tópico anterior.

A etapa seguinte foi caracterizada pela Exploração, Síntese e Implicações de Design (Hanington e Martin, 2012). Esta etapa sugere a pesquisa e análise das temáticas do projeto e um melhor entendimento do mercado e público alvo. No caso deste projeto, esta etapa correspondeu à compreensão e adaptação do processo artesanal de reciclagem de polímeros; ao entendimento de como os produtos similares se apresentam no mercado; como o público enxerga a reciclagem dos materiais plásticos e possíveis produtos oriundos destes materiais, sendo feita, a partir disso, a caracterização dos usuários.

A etapa 3 consistiu na Geração de Conceito. Para tanto, a conceituação e o desenvolvimento da linha de acessórios a partir de resíduos plásticos reciclados considerou os principais temas abordados na fundamentação teórica e na análise das demais temáticas de projeto. Para isso, foram utilizadas ferramentas que auxiliaram na ideação de um conceito, como a experimentação visual a partir de ensaios práticos com o material; a proposta conceitual, por meio de uma modelagem verbal; o painel semântico de conceito; e a geração de alternativas.

Na quarta etapa, a prototipação se deu após a geração de alternativas e escolha dos acessórios a serem produzidos. Foram listados e selecionados os materiais a serem aplicados e, em seguida, foi realizada a confecção das peças finais, com maior refinamento.

\section{RESULTADOS}

Neste tópico são apresentados, resumidamente, os principais resultados alcançados durante o desenvolvimento da coleção autoral de acessórios. Neste recorte foi dado destaque para entendimento e adaptação de processos artesanais de reciclagem por meio de experimentos realizados; compreensão das características do público alvo desta coleção; experimentações visuais do material; conceituação e geração de propostas; bem como da prototipagem final da coleção. 


\subsection{Análise e adaptação do processo artesanal de reciclagem de polímeros}

Os processos industriais tradicionais de reciclagem do plástico envolvem etapas que utilizam maquinários específicos para procedimentos, como a granulação, moagem e extrusão do plástico. $O$ tamanho e preço dessas máquinas inviabiliza o processo industrial para pequenos produtores, o que torna popular as adaptações caseiras e os DIY (Do it Yourself - Faça você mesmo).

Considerando o processo artesanal de reciclagem foram encontrados conteúdos em livros, plataformas open source e vídeos DIY, com apresentação de ferramentas, vídeo aulas e até desenhos técnicos de máquinas possíveis de serem construídas para a reciclagem do plástico

Baseado em Fraga (2014), na plataforma Precious Plastic (HAKKENS, 2013, web) e em vídeos DIY disponíveis no Youtube, foi realizada uma análise dos processos de reciclagem artesanal de plásticos, contemplando as principais etapas do procedimento, incluindo o tempo necessário para cada uma delas. Após as análises, foi realizada a experimentação do processo artesanal de reciclagem.

$\mathrm{Na}$ figura 01 são apresentadas as etapas do processo artesanal de reciclagem, baseadas em Fraga (2014), o que possibilita dar um panorama dos procedimentos. $O$ tempo de cada etapa pode variar de acordo com o tipo de plástico e fatores externos como temperatura, umidade, etc.

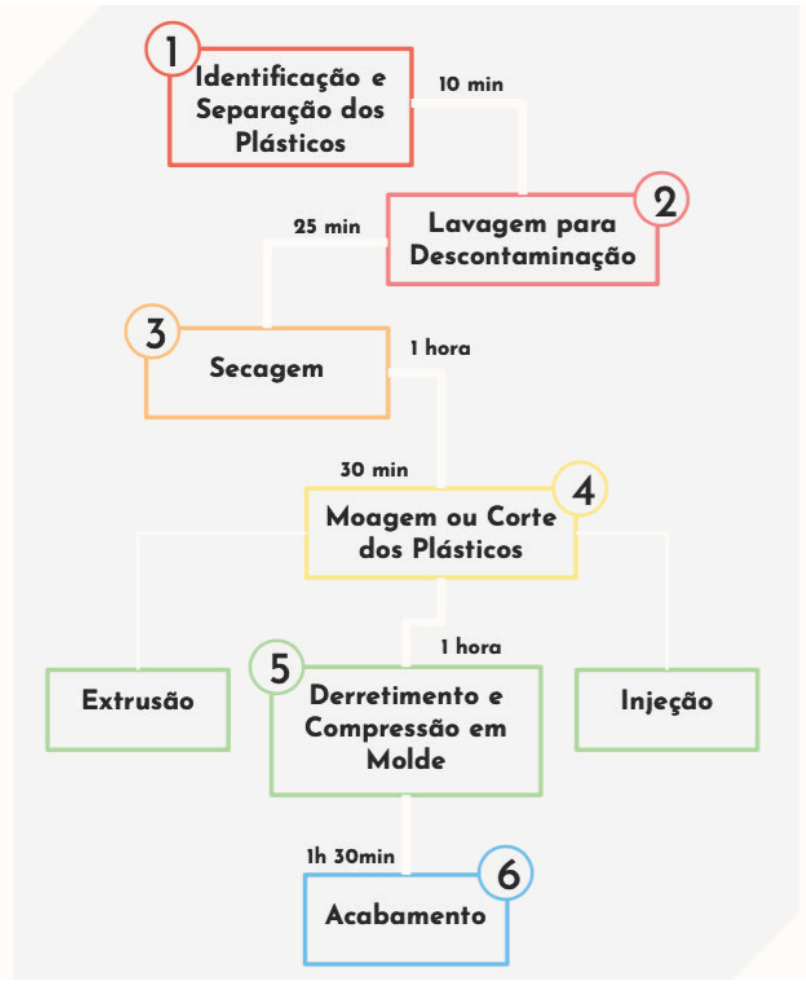

Figura 01 - Análise de Processo Artesanal de Reciclagem. Fonte: Beppler (2019).
As primeiras etapas, que incluem identificação e separação do material, foram realizadas de forma manual, observando-se os rótulos ou marcações na embalagem. Nos testes iniciais, foi necessário validar a utilização combinada de diferentes tipos de plásticos, também encontrados em embalagens e tampas, normalmente compostas de PVC, PP ou PET, assim como de PEAD, plástico citado anteriormente como visado para este trabalho. As tampas presentes nestas embalagens, por serem peças pequenas, normalmente não acompanham a identificação de sua composição, de modo que foi necessário um derretimento teste para identificação do ponto de fusão.

A partir disso, foi realizada a etapa de lavagem/ descontaminação e em seguida a secagem dos materiais selecionados. A figura 02 ilustra o processo aplicado em uma embalagem de shampoo.

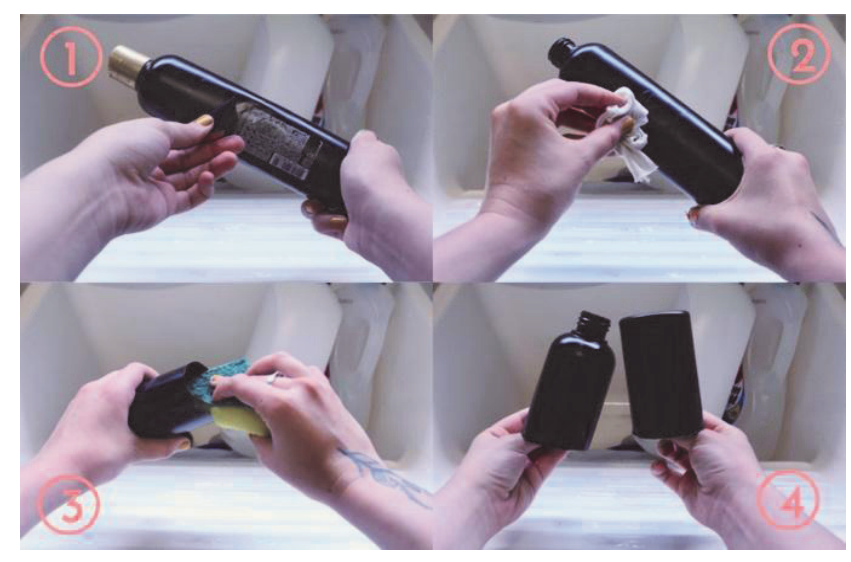

Figura 02 - Lavagem e Descontaminação. Fonte: Beppler (2019).

Com os materiais secos, sucedeu-se o processo de corte do material em pequenos quadrados, utilizando uma tesoura. Para o derretimento, foi utilizada primeiramente uma fôrma de alumínio e um forno elétrico a 120 graus por 40 minutos, com uma mistura de PEAD (embalagem branca) e outros materiais plásticos, provenientes de tampas (cores amarelo e vermelho) de plásticos não identificados. Após 40 minutos, com uma colher de metal, os plásticos foram levemente pressionados e novamente colocados no forno por outros 30 minutos. Passado esse tempo, o material foi retirado da fôrma de alumínio e posicionado entre duas chapas de vidro, estas em temperatura ambiente, para serem prensados com o auxílio do torno de bancada. Foi possível perceber a falta de homogeneidade na peça final dada pela combinação dos diferentes tipos de plásticos; os materiais não identificados não derreteram em totalidade por não atingirem sua temperatura de fusão. Por isso, optou-se pela realização 
de testes exclusivos com o PEAD. A figura 03 mostra as etapas de derretimento e o resultado obtido com um dos primeiros testes realizados.

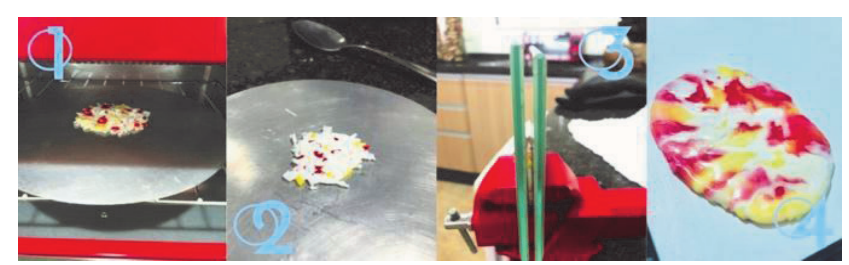

Figura 03 - Primeiros testes com o material Fonte: Beppler (2019).

Nos testes em que foi derretido apenas o PEAD, foram obtidos resultados diferentes aos do teste anterior e foi possível observar outros pontos, como o tempo para derretimento total do material; a influência do formato do material a ser derretido; melhor molde e forma para derreter e comprimir o plástico; assim como a necessidade de utilização de desmoldante para facilitar a retirada do material. Na figura 04 é possível verificar a diferença entre as peças oriundas do PEAD isolado, das peças em que foram adicionados plásticos não identificados.

Como citado anteriormente, o ponto de fusão do Polietileno de Alta Densidade é em torno de $130^{\circ} \mathrm{C}$. Desse modo, a acadêmica utilizou os valores entre $130^{\circ} \mathrm{C}$ e
Notou-se que além de possibilitar misturar o material quando quente, o formato em que os plásticos eram cortados também influenciava nos padrões e efeitos gerados após o derretimento. Desse modo, como indicado na figura 05 , os demais testes foram realizados com as embalagens cortadas em pequenas tiras, quadrados maiores, menores e irregulares para a experimentação de estilos.

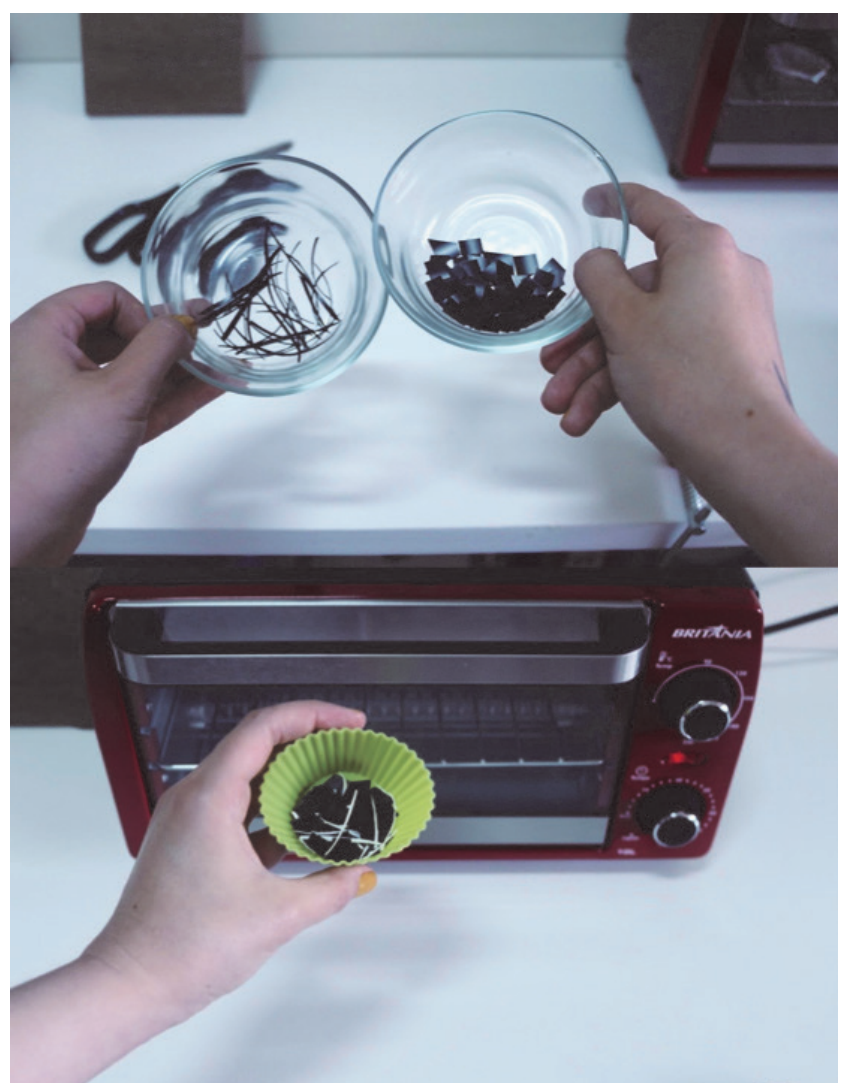

Figura 05 - Formatos de corte dos materiais. Fonte: Beppler (2019).

Nos primeiros testes, independente de serem ou não comprimidos, os plásticos apresentavam formatos e texturas bastante rústicos e irregulares, o que demandou grande tempo de acabamento final. Buscou-se então aprimorar o processo para que as peças apresentassem um maior refinamento. Assim, foi realizado o derretimento do plástico em cima de uma pequena chapa de vidro e após derretido, foi pressionado contra outra chapa de vidro, novamente utilizando-se um torno de bancada. Pode-se perceber com esse teste, como mostra na figura 06 , que o lado que derreteu no vidro ficou totalmente liso e homogêneo (número 1), enquanto o lado em que o vidro que estava em temperatura ambiente pressionou, ficou irregular e heterogêneo (número 2). Portanto, entendeu-se ser necessário o aquecimento de ambos os vidros para um acabamento refinado das peças. 


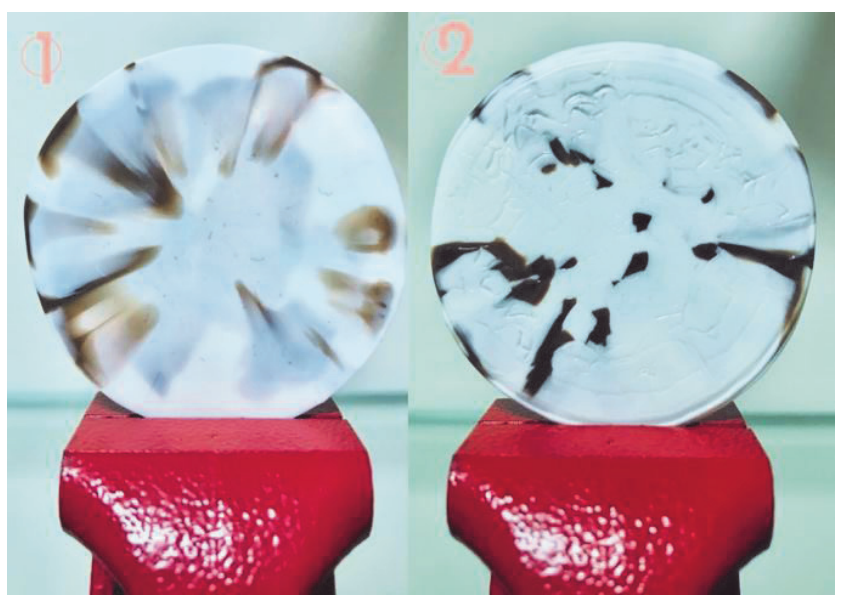

Figura 06 - Teste de Refinamento

Fonte: Beppler (2019).

Com a validação do processo artesanal de reciclagem, foi possível identificar os pontos que ainda demandavam adaptação após a análise do processo, realizada anteriormente. A partir disso, pode-se refinar todas as etapas para a fabricação da coleção de acessórios.

\subsection{Caracterização do público alvo}

Para identificar o potencial público alvo desta coleção, foi aplicado um questionário online que abrangeu questões relacionadas aos hábitos de consumo dos respondentes e como viam o material plástico. Procurou-se também identificar como os participantes veem as questões ambientais e os impactos gerados pelos resíduos plásticos.

A pesquisa contou com a participação de 114 pessoas, sendo $80 \%$ dos respondentes do gênero feminino. Os resultados permitiram tangibilizar informações referentes aos hábitos de consumo destas pessoas, bem como identificar os principais materiais plásticos descartados por eles. Os participantes se mostram conscientes sobre a temática ambiental, embora não consumam produtos de origem sustentável regularmente, sendo essa uma possibilidade de difusão da cultura circular de consumo.

Como resultado da análise dos dados da pesquisa, foi aplicada a ferramenta persona para criar uma representação visual do público ao qual se destina esta coleção de acessórios. Também serviu como base para a elaboração da persona uma análise realizada pelo site WGSN, de empresa especializada em tendências. Essa plataforma divide o consumidor de 2021 em quatro grandes grupos: The Compressionists, Market Makers, Cyber Cynics e Kindness Keepers. Os Market Makers e Kindness Keepers serviram de embasamento para a construção da persona: consumidores que ressaltam a praticidade na hora de consumir ao mesmo tempo que procuram e apoiam marcas que investem no social. Almejam mudanças sociais e querem deixar sua marca no mundo (WGSN, 2019). A figura 07 apresenta o painel de persona elaborado.

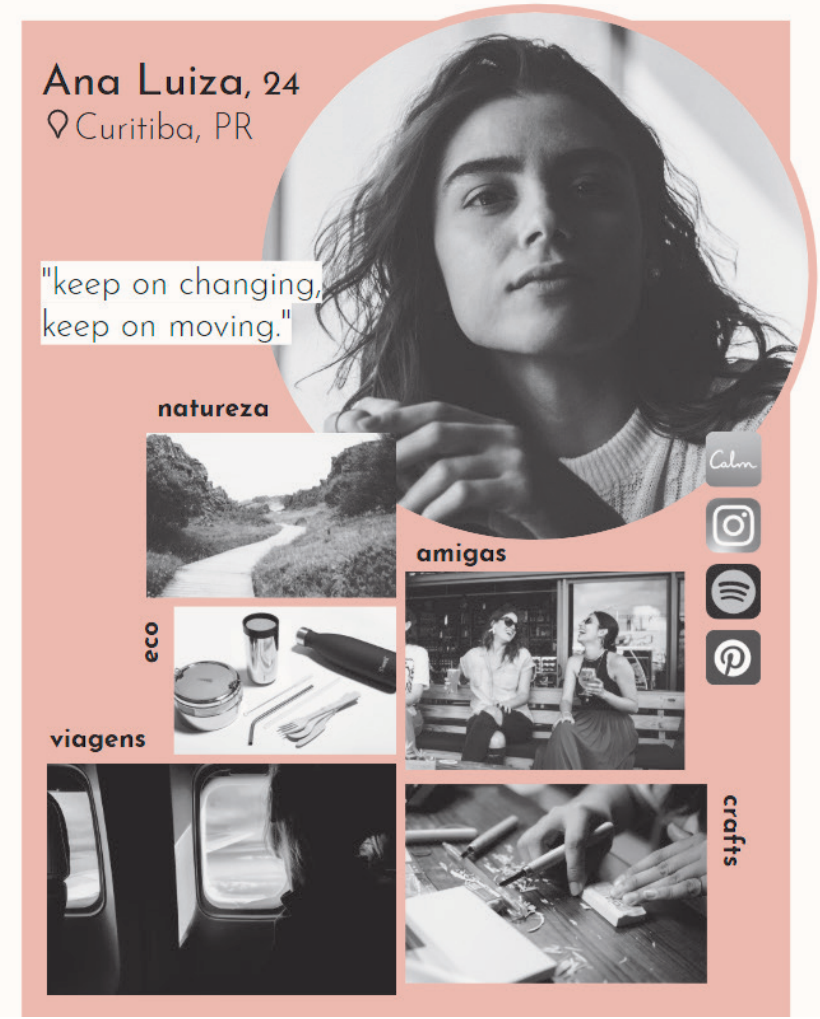

Figura 07 - Painel persona Fonte: Beppler (2019).

Observa-se em comum às pessoas pertencentes a este público alvo a necessidade de serem autênticas, que visam de diferenciar das demais, mas que ao mesmo tempo se preocupam com temas atuais.

Deste modo, há uma preocupação com questões ambientais, que motivam o querer conhecer de onde vem os produtos que estão sendo adquiridos, bem como o tipo de material utilizado na confecção destes produtos.

\subsection{Experimentações visuais}

Para a conceituação e o desenvolvimento da linha de acessórios, foram realizados testes visuais a partir da experimentação de cores, tamanhos e formatos gerados pelo processo com o material.

Por se tratar de um tipo de plástico presente em grande parte das embalagens consumidas e descartadas, o PEAD apresenta uma grande variedade de cores no mercado.

Nestes experimentos foi aplicada a variação no corte dos plásticos para se observar os efeitos que poderiam resultar. Com as combinações de cores surgiram resultados variados, conforme observado na figura 08. 


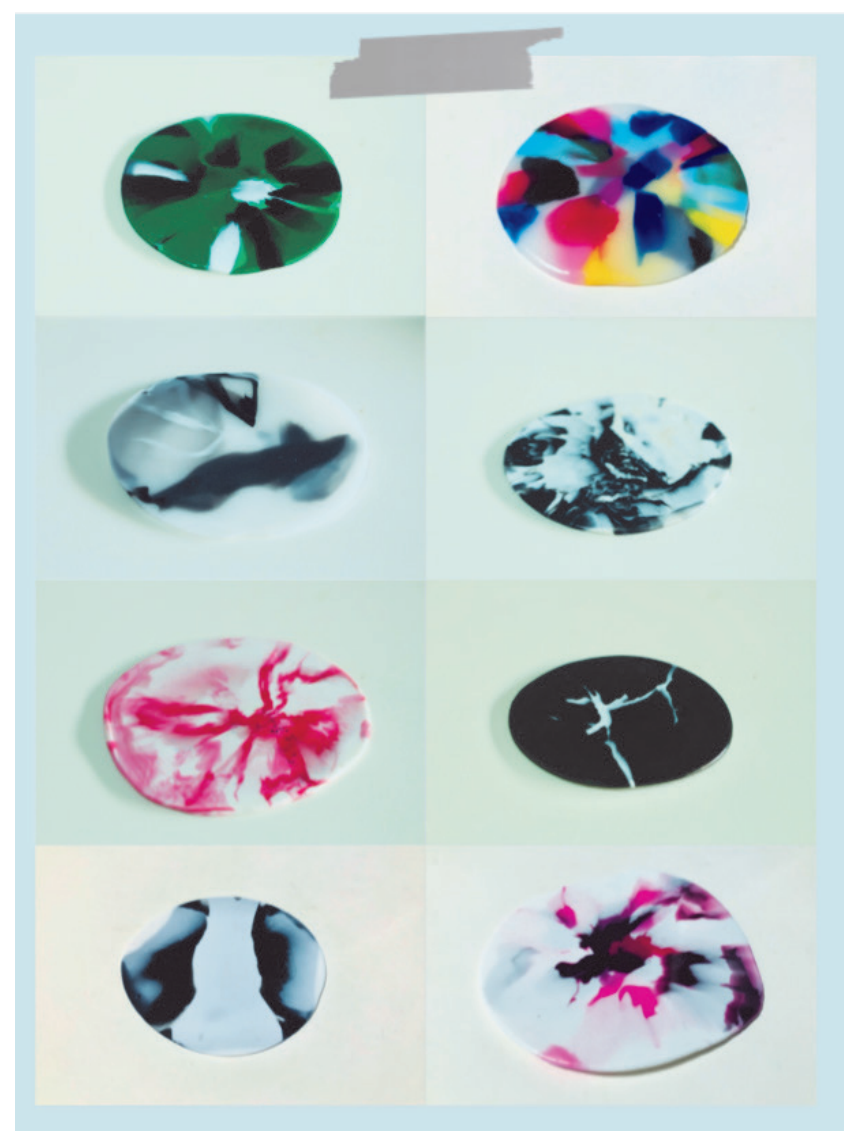

Figura 08 - Testes cromáticos Fonte: Beppler (2019).

A cada experimentação realizada foi possível identificar um novo e diverso padrão único e distinto dos demais, apesar de algumas similaridades presentes na constante repetição do aspecto abstrato. Pela observação deste padrão contínuo, resultado da combinação entre o refinamento do processo de fabricação e a mistura de cores e formatos da matéria-prima, identificou-se a base conceitual desta coleção.

\subsection{Conceito e geração de propostas}

Decorrente das experimentações realizadas no tópico anterior, observou-se que, apesar de normalmente resultar numa forma circular com contornos irregulares, as formas originadas internamente nas peças eram abstratas. Isso levou a se trabalhar conceitualmente com a proposta do abstrato.

O abstrato se manifesta em diferentes contextos: na gramática, na arte e na filosofia. A arte é uma grande veiculadora de significados e ressignificações, sendo o estilo abstrato uma oportunidade material de ressignificação para cada observador.
Para esta coleção, as peças foram inspiradas na abstração da natureza juntamente ao abstracionismo geométrico de Wassily Kandinsky - trabalhadas a partir da ressignificação dada aos plásticos de consumo doméstico - que, para cada pessoa, apresentam um sentido único, que se construirá no inconsciente individual.

A proposta foi aplicar cores, texturas e formatos como forma de abstração, de reflexão sobre o modo de consumo atual e utilização do plástico, bem como sobre o impacto que ele causa na vida do planeta e na vida de cada ser humano.

A geração de propostas formais deu continuidade ao processo de experimentação visual e à análise que originou o conceito da coleção. Para contribuir com a geração destas propostas foram selecionadas três obras de Wassily Kandinsky que contribuíram como inspiração para a concepção das propostas, por meio de elementos encontrados nas respectivas obras. Os quadros foram selecionados a partir de pesquisa online, sendo eles: Composition VIII de 1923; Circles in a Circle, também de 1923, e Three Sounds, de 1926.

Procurou-se identificar nos quadros, cores e formas recorrentes nas obras do artista. As cores encontradas nas pinturas foram referenciadas a partir da escala Pantone e buscou-se então, equipará-las às cores das embalagens recolhidas na coleta de materiais.

Observa-se nas obras analisadas que Kandinsky faz uso de cores diversas combinadas a variados formatos geométricos. $\mathrm{O}$ artista faz também uso das linhas, que ao se cruzarem em seus quadros, cortam as formas dispostas dando origem a novas figuras.

Com estas informações em mãos, foi elaborada a geração manual de propostas, sendo contempladas as peças teste previamente confeccionadas, juntamente com outros materiais que servem para a fabricação de acessórios. O resultado gerado destaca que, assim como nas obras analisadas de Kandinsky, as linhas têm um papel bastante expressivo, decorrente de cortes experimentais, criando a possibilidade de novas formas em combinação com os artigos para fabricação de acessórios de diferentes cores e materiais. A figura 09 apresenta o desenvolvimento das propostas geradas.

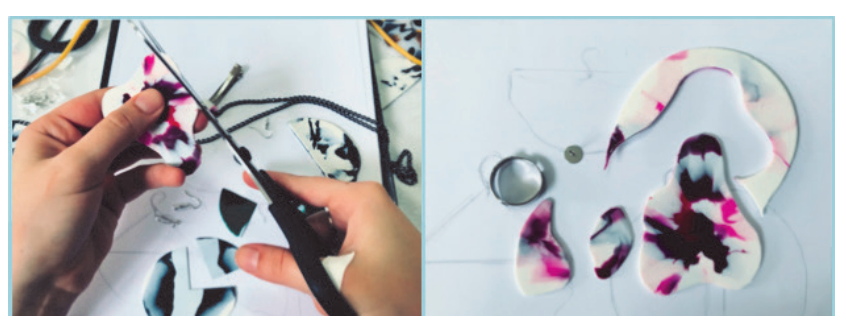




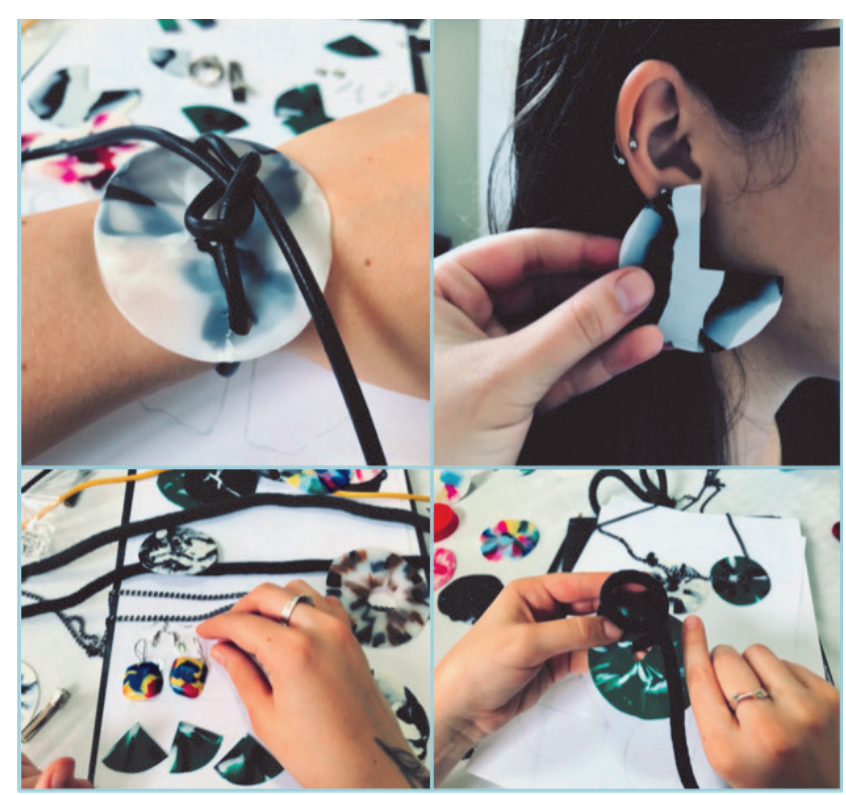

Figura 09 - Testes cromáticos Fonte: Beppler (2019).

Tendo em mente as principais características propostas no conceito da coleção, buscou-se avaliar neste processo as possíveis combinações entre forma, cor e materiais disponíveis. Foram evidenciadas as formas presentes no abstracionismo geométrico, resultante dos cortes do material, somado à necessidade de se aproveitar todas as partes das peças plásticas.

Pretendeu-se também, que o processo envolvesse pouca complexidade para produção. Desse modo, optou-se pela utilização dos materiais adicionais na cor preta, referenciando as inúmeras linhas, traços e contornos presentes nas obras.

\subsection{Protótipos finalizados}

Uma prototipação inicial ocorreu após a geração das propostas e da escolha dos acessórios a serem produzidos. Para dar sustentação e acabamento às peças, optou-se por utilizar materiais disponíveis no mercado e que são comumente usados para a confecção de bijuterias.

A coleção é composta por nove acessórios divididos em três segmentos, apoiados nas cores e elementos das obras de Kandinsky, sendo cada segmento composto por um anel, um colar e um par de brincos.

O segmento número 01 da coleção é composto por um anel fabricado inteiramente com o PEAD, brincos com pinos de metal e um colar composto por duas peças sustentadas por um cordão de couro e fechos magnéticos. A figura 10 apresenta os protótipos iniciais deste segmento, pouco refinados, juntamente ao quadro que serviu de referência para este segmento.

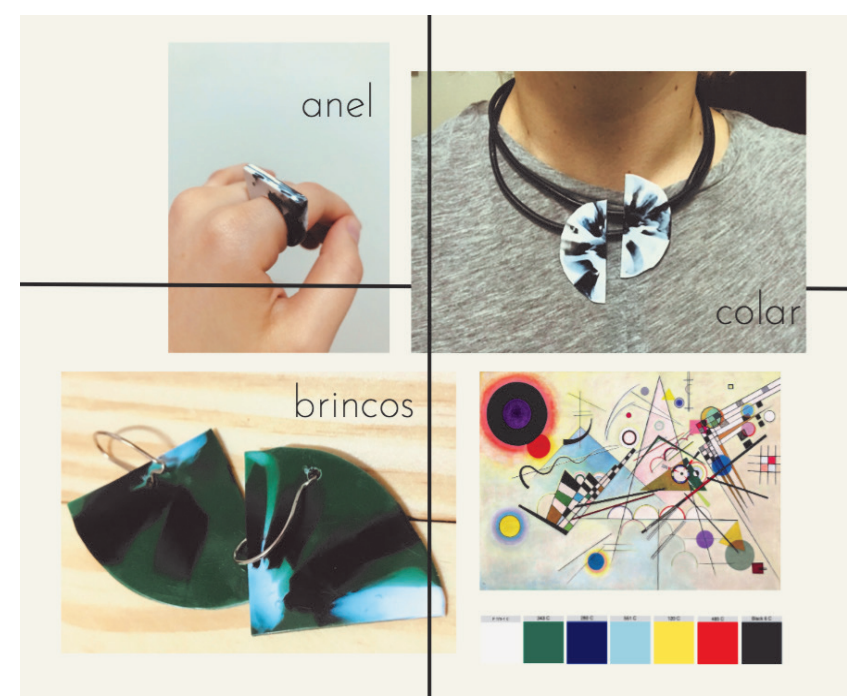

Figura 10 - Modelos iniciais do segmento número 01 Fonte: Beppler (2019).

O segundo segmento é caracterizado por peças circulares, sendo composto por dois brincos complementares com pinos de metal na parte de trás, um anel com sustentação de metal ajustável e um colar com uma peça vazada entrelaçada por um cordão de algodão. Observa-se na figura 11 os elementos trabalhados nesta proposta.

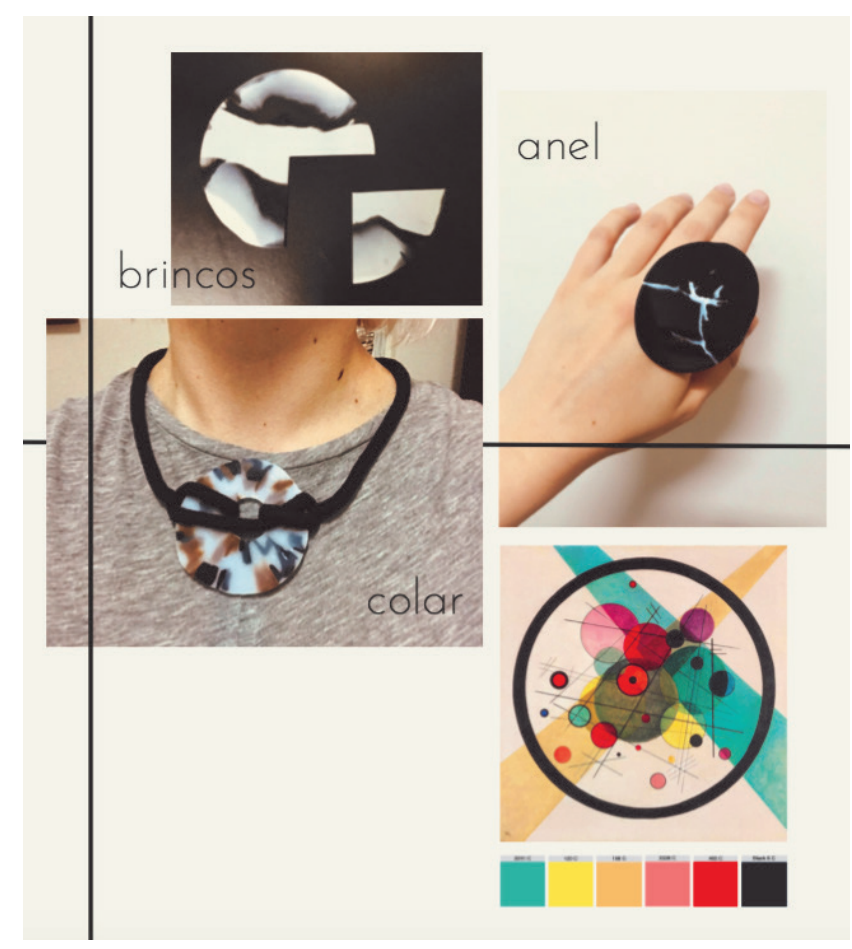

Figura 11 - Modelos iniciais do segmento número 02 Fonte: Beppler (2019).

O segmento número três consiste em peças com cores mais vivas, contrastadas com o plástico translúcido. Este segmento é composto por um anel de cores variadas e 
base de metal ajustável, brincos complementares com pinos de metal e um colar sustentado nas laterais por cordões de algodão. Na figura 12 são apresentadas as peças desenvolvidas para este segmento.

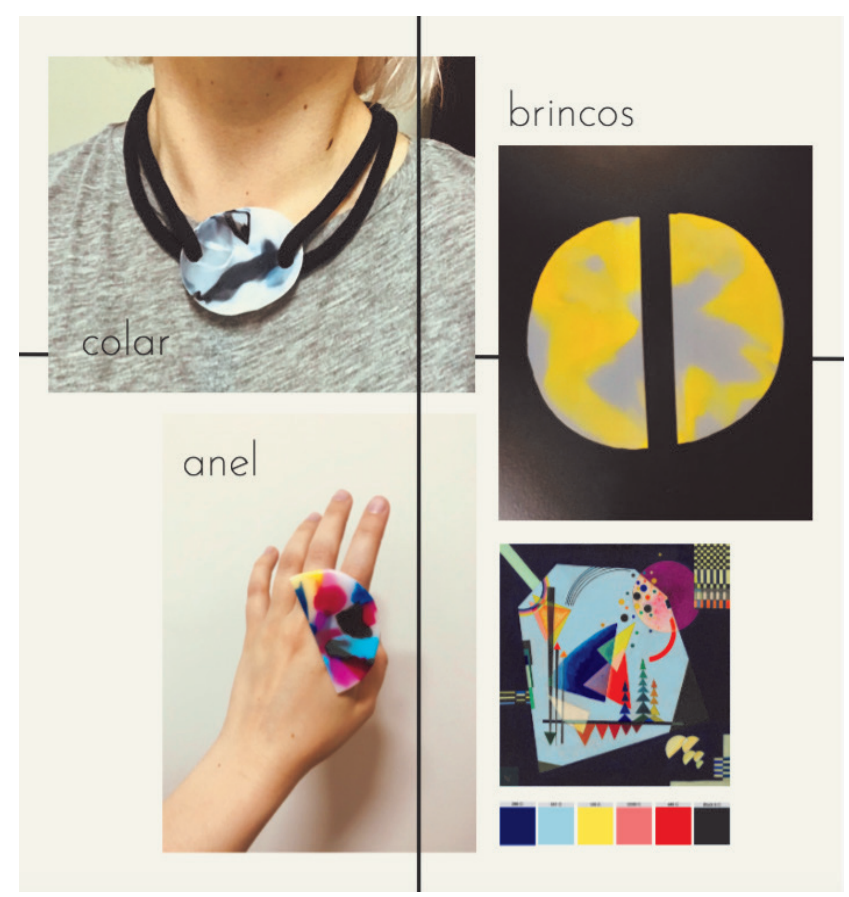

Figura 12 - Modelos iniciais do segmento número 03 Fonte: Beppler (2019).

Os materiais complementares foram selecionados por serem compatíveis às soluções concebidas na geração de alternativas, sendo eles: tarrachas de silicone e pinos de níquel para brincos; fecho magnético para colar; fecho de metal para colar; base de níquel com tamanho regulável para anéis; corda de algodão para colar; cordão de couro para colar; correntes de metal para colares.

A partir da confecção dos protótipos iniciais, foi possível observar as melhorias necessárias para um melhor acabamento nas peças finais, assim como testar a aplicação com os materiais de suporte e sua fixação.

Devido à quantidade de plástico utilizado, as peças possuem diferentes grossuras. As peças mais finas puderam ser cortadas com tesoura, já para as peças mais grossas, exigiram o uso de uma micro-retífica. A ferramenta também foi utilizada para perfurar o anel do segmento número um e garantir uma lixação inicial nas peças.

Foi identificado também que para a confecção e acabamento dos acessórios, seria necessário lixar as peças com lixa d'água e foram realizados testes com diferentes colas para a verificação da aderência aos materiais de suporte. As cores identificadas em cada obra foram aplicadas nos protótipos finais.
A prototipação final das peças do segmento número é apresentada na figura 13. Este segmento foi baseado na obra Composition VIII (figura 27) e é composto por um anel fabricado inteiramente com PEAD, brincos com pinos de metal e um colar composto por duas peças sustentadas por um cordão de couro e fechos magnéticos.

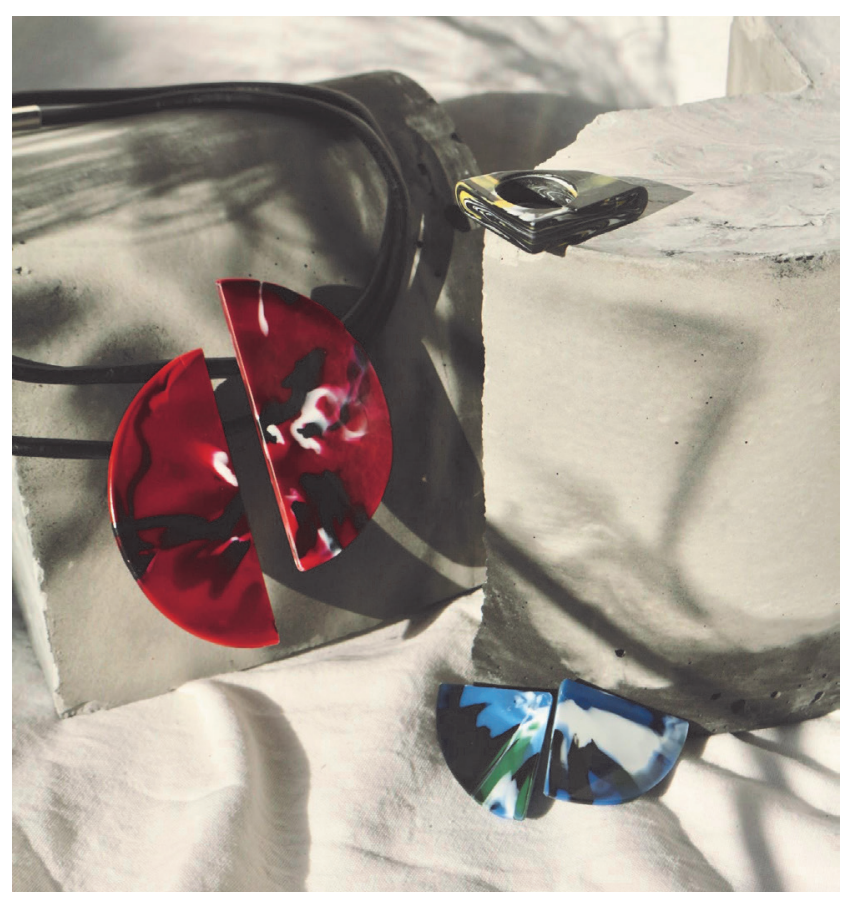

Figura 13 - Protótipo final segmento um Fonte: Beppler (2019).

O segundo segmento é referenciado na obra Circles in a circle, caracterizado por peças circulares, ponto principal na temática do quadro. O segmento é composto por dois brincos complementares com pinos de metal na parte de trás, um anel com sustentação de metal ajustável e um colar com uma peça vazada entrelaçada por um cordão de algodão, apresentado na figura 14.

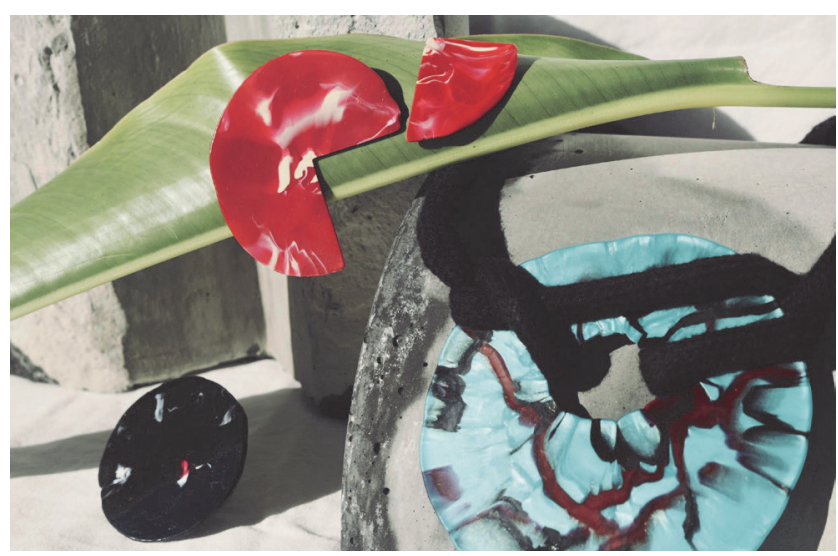

Figura 14 - Protótipo final segmento dois Fonte: Beppler (2019). 
Por fim, O segmento três consiste num conjunto com aplicação de cores mais vivas em contraste ao plástico translúcido utilizado. Este segmento é composto por um anel de cores variadas e base de metal ajustável, brincos complementares com pinos de metal e um colar sustentado nas laterais por cordões de algodão. Este segmento foi inspirado na obra Three Sounds, conforme se observa na figura 15.

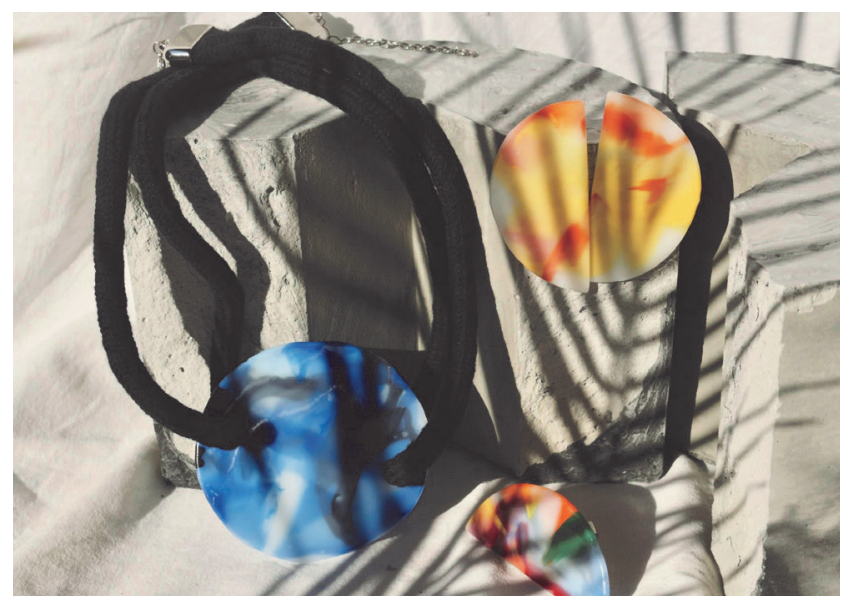

Figura 15 - Protótipo final segmento três

Fonte: Beppler (2019).

A figura 16 apresenta a coleção final de acessórios proveniente da utilização de resíduos plásticos elaborados a partir da reciclagem artesanal de materiais plásticos.

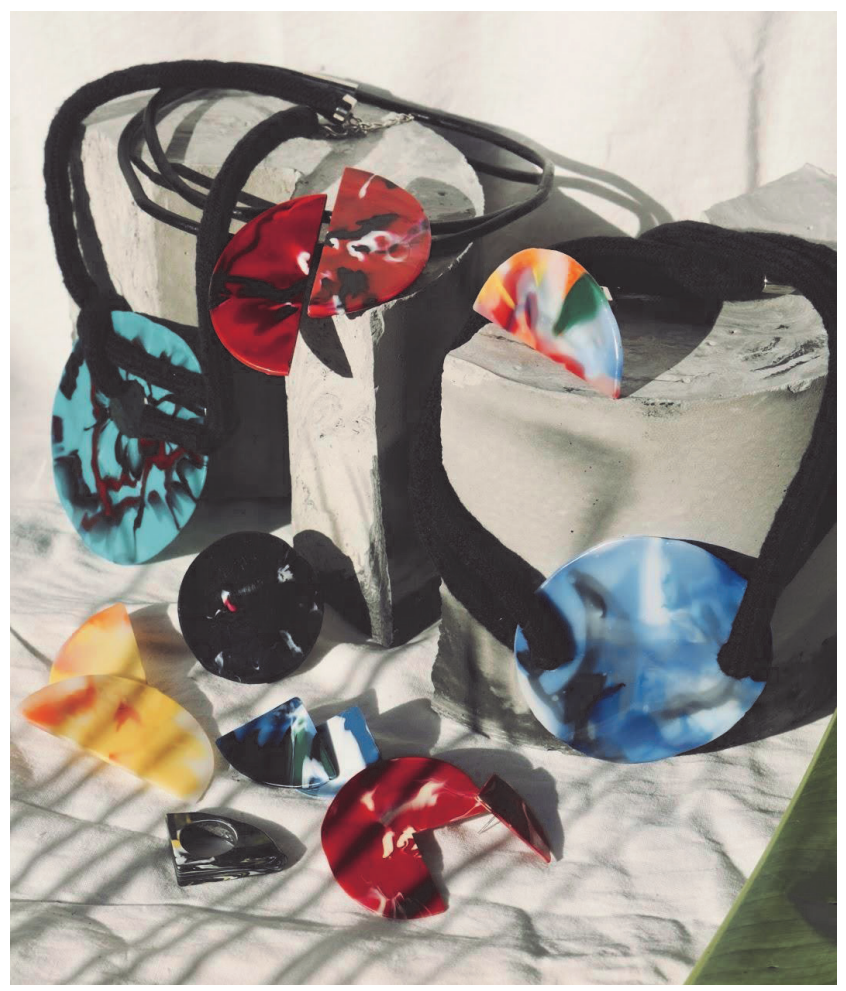

Figura 16 - Protótipos da coleção final de acessórios Fonte: Beppler (2019).
Os protótipos foram produzidos visando gerar o mínimo de resíduos possível, com a viabilidade de reaproveitar todos os retalhos plásticos e até mesmo os próprios acessórios, se não mais utilizados, na fabricação de novos produtos, garantindo a circularidade da coleção desenvolvida.

\section{CONSIDERAÇÕES FINAIS}

Este artigo apresentou os resultados do Trabalho de Conclusão de Curso em Design, desenvolvido e apresentado em 2019, que teve por objetivo desenvolver uma coleção autoral de joias a partir da reciclagem artesanal do PEAD. Este desenvolvimento projetual buscou responder à problemática de como o design de produtos pode incorporar o uso dos resíduos plásticos a um ciclo sustentável de consumo.

Para a estruturação e direcionamento do trabalho, foram utilizadas as etapas da metodologia proposta por Hanington e Martin (2012) como: (i) Planejamento, Escopo e Definição do projeto; (ii) Exploração, Síntese e Implicações de Design; e (iii) Geração de Conceito e Prototipagem Inicial.

Para aprofundamento da problemática foram explorados, no tópico dois deste artigo, estudos teóricos que abordaram os polímeros, seu descarte e impacto ambiental gerado, reciclagem e seus processos; sustentabilidade, ciclo sustentável de consumo e design sustentável.

Como forma de procurar combater a problemática dos resíduos plásticos, dentre outros fatores prejudiciais à vida no planeta, a Organização das Nações Unidas, juntamente com diversos líderes mundiais, lançou em 2015 a agenda 2030 para o desenvolvimento sustentável, com um conjunto de 17 Objetivos de Desenvolvimento Sustentável (ODS). Estes objetivos visam, dentre outros, erradicar a pobreza, proteger a vida na terra e garantir paz e prosperidade para todas as pessoas. Alguns destes objetivos estão diretamente relacionados com a proposta deste projeto, como trabalhar em prol do desenvolvimento sustentável, como também cuidados com a conservação da vida marinha, uma vez que os resíduos plásticos são considerados um dos maiores agressores ao meio ambiente.

A proposta do projeto vislumbrou possibilitar utilizar como matéria-prima, resíduos plásticos gerados nas residências; por isso o foco dado à reciclagem artesanal. Nesse sentido, este estudo permitiu um maior entendimento sobre o processo artesanal de reciclagem e um aprofundamento sobre como reutilizar e ressignificar estes resíduos, em especial do PEAD.

Na segunda etapa do projeto, fez-se uso de ferramentas para auxiliar na análise e validação de processo artesanal de reciclagem, processos esses que foram a parte mais elaborada e fundamental do trabalho. Isso, pois 
possibilitaram a constatação de como reutilizar e ressignificar os resíduos plásticos. Neste artigo, foram destacados a análise e adaptação do processo artesanal de reciclagem de polímeros, como também a caracterização do público alvo.

O artefato escolhido para aplicar a ressignificação do resíduo foi a joia. A escolha deste artefato considerou o contraponto que está relacionado a ele (joia $\mathrm{x}$ resíduo), corroborando com uma ressignificação do material, como também por acompanharem a história da humanidade e traduzirem a cultura e costumes de diversos povos ao longo dos séculos.

Por muitos séculos, os acessórios foram fabricados a partir de materiais nobres como ouro, prata e pedras preciosas, sendo considerados símbolos de riqueza e status. Com o descobrimento de outros materiais, principalmente os sintéticos, surgiram alternativas mais econômicas para as matérias-primas preciosas; o próprio artefato em si foi tendo seu conceito ressignificado. Compreendendo os impactos ambientais que a extração de metais ocasiona, bem como o impacto deixado pelo descarte inapropriado de resíduos plásticos, este projeto permitiu compreender a necessidade e a importância de trazer um novo significado para o resíduo plástico. Por meio dele, reforçou-se um novo espaço para o resíduo, introduzindo-o num lugar, que por centenas de anos foi destinado a pedras e outros metais preciosos.

Na terceira etapa, elaborou-se o conceito da coleção de acessórios que foi concebida a partir da experimentação visual com o material. O conceito da coleção veio de encontro com a necessidade de ressignificação do material plástico e a identidade abstrata das peças oriundas do processo de reciclagem. Ao explorar essas duas temáticas foi realizado um paralelo com os resultados artísticos do movimento abstracionista geométrico e na abstração da natureza.

A partir disto, foi produzida a prototipação da coleção, que foi elaborada com o auxílio de materiais para o refinamento e sustentação das peças plásticas. A coleção é composta de nove peças no total, divididas em três segmentos.

Considera-se que os resultados apresentados neste artigo auxiliaram na caracterização dos principais resíduos utilizados domesticamente e na busca por soluções para a destinação dos resíduos plásticos. A exploração dos processos de reciclagem artesanais de plásticos visou, também, contribuir para influenciar na disseminação do importante papel de um ciclo sustentável de consumo, assim como com a conscientização do impacto do consumo excessivo e descarte irregular de resíduos plásticos.
Com tudo isso, além questão ambiental, para reutilizar e ressignificar os resíduos plásticos, a contribuição deste artigo explora também o foco na questão econômica, uma vez que possibilita um novo modo de se produzir artefatos por meio de uma reciclagem artesanal, como também social, pois torna estes artefatos mais acessíveis a diferentes públicos.

A implementação de uma economia circular, em paralelo com um ciclo sustentável de consumo, é essencial e necessária para a manutenção do meio ambiente e consequentemente da sociedade como um todo. É de enorme benefício que os indivíduos e grandes indústrias, adotem práticas de consumo e produção circular e sustentável.

\section{REFERÊNCIAS}

ABRELPE, Associação Brasileira de Empresas de Limpeza Pública e Resíduos Especiais. Panorama dos resíduos sólidos no Brasil, 2017. São Paulo, 2018.

BELCHIOR, Camilo. Ressignificação, uma possível estratégia para a sustentabilidade no século XXI, 2017. Disponível em: <http://www.designbrasil.org.br/entre-aspas/ressignificacao-uma-possivel-estrategia-para-sustentabilidade-no-seculo-xxi-parte-1/>. Acesso em: 16 abr. 2019.

DIAS, Reinaldo. Sustentabilidade: Origem e Fundamentos; Educação e Governança Global; Modelo de Desenvolvimento. São Paulo: Editora Atlas S.A., 2015.

ELLEN MACARTHUR FOUNDATION. Rumo à Economia Circular: o racional de negócio para acelerar a transição. 2015. Disponível em https://www.ellenmacarthurfoundation.org/assets/downloads/Rumo-àeconomia-circular_Updated_08-12-15.pdf. Acesso em: 10 fev 2020.

. The New Plastics Economy: Rethinking the future of plastics. Inglaterra: 2016.

FRAGA, Simone Carvalho Levorato. Reciclagem de materiais plásticos: aspectos técnicos, econômicos, ambientais e sociais. 1. ed. São Paulo: Érica, 2014.

GEGER, Léa; TENNENBAUM, Carla. Os Três Princípios do Design Circular: Cradle to Cradle. Ideia Circular, 2017. HAKKENS, Dave. Precious Plastic. 2013. Disponível em: <https://preciousplastic.com/en/mission.html>. Acesso em: 15 abr. 2019.

HANINGTON, Bruce; MARTIN, Bella. Universal Methods of Design: 100 Ways to Research Complex Problems, Develop Innovative Ideas, and Design Effective Solutions. Estados Unidos da América: Editora Rockport, 2012. 
IPEA, Instituto de Pesquisa Econômica Aplicada. Situação Social das Catadoras e dos Catadores de Material Reciclável e Reutilizável. Brasília: Livraria IPEA, 2013.

MANZINI, Ezio; VEZZOLI, Carlo. Design for Environmental Sustainability. Itália: Editora Zanichelli, 2008.

NAÇÕES UNIDAS NO BRASIL. ONU Meio Ambiente aponta lacunas na reciclagem global de plástico. Disponível em: <https://nacoesunidas.org/onu-meio-ambiente-aponta-lacunas-na-reciclagem-global-de-plastico/>. Acesso em: 15 abr. 2019.

NUNES, Edilene de Dutra; LOPES, Fábio Silva. Polímeros: conceitos, estrutura molecular, classificação e propriedades. 1. ed. São Paulo: Érica, 2014.

PAZMINO, Ana Verónica. Uma reflexão sobre Design Social, Eco Design e Design Sustentável. 2007. Disponível em: <http://naolab.nexodesign.com.br/ wp-content/uploads/2012/03/PAZMINO2007-DSocialEcoD-e-DSustentavel.pdf>. Acesso em: 16 abr. 2019.

WGSN. Future Consumer 2021. Disponível em: $<$ https://lp.wgsn.com/form-nrf-tech-fy19q2.html?utm_source=banner-ad\&utm_medium =website-third-party\&utm_content=future-consumer-2021\&utm_campaign=nrf-tech-trendtalk>. Acesso em: 20 abr. 2019

ZANIRATO, Sílvia Helena; ROTONDARO, Tatiana. Consumo, um dos dilemas da sustentabilidade. 2016. Disponível em: <http://www.scielo.br/scielo.php?pi$\mathrm{d}=$ S0103-40142016000300077\&script=sci_arttext $>$. Acesso em: 16 abr. 2019.

\section{AUTORES}

\section{ORCID: -}

CHIARA ALINE BEPPLER | Univille - Design | Joinville, SC Brasil ! End. para correspondência: Rua Prefeito Helmuth Fallgatter 785, casa 20 | Boa Vista | 89205-300 ! email: chiarabeppler@gmail.com

ORCID: https://orcid.org/0000-0002-9082-880X

ISADORA BURMEISTER DICKIE, Dra. | Univille - Design | Joinville, SC - Brasil | End. para correspondência: Rua Dr. João Colin, 2875/01 | Santo Antônio | Joinville, SC | 89218-035 | email: isadora.dickie@gmail.com

ORCID: https://orcid.org/0000-0001-7560-9871

ADRIANE SHIBATA DOS SANTOS, Dra. | Univille - Design | Joinville, SC - Brasil | End. para correspondência: Rua Ernesto Ravache, 134 apto 402 | Santo Antônio | Joinville, SC | 89.218-165 | email: adriane.shibata@univille.br

\section{COMO CITAR ESTE ARTIGO}

BEPPLER, Chiara Aline; DICKIE, Isadora Burmeister; SANTOS, Adriane Shibata dos. Coleção Autoral de Joias: Uma Experiência Prática A Partir da Reciclagem Artesanal de Polímeros. MIX Sustentável, [S.I.], v. 6, n. 2, p. 149-162, mai. 2020. ISSN 24473073. Disponível em:<http://www.nexos.ufsc.br/index.php/ mixsustentavel>. Acesso em: dia mês. ano. doi:https:// doi.org/10.29183/2447-3073.MIX2020.v6.n2.149-162.

DATA DE ENVIO: 27/04/2020

DATA DE ACEITE: 30/04/2020 
